\title{
EDITORIAL
}

\section{The World Molecular Imaging Society (WMIS)}

\author{
Robert J. Gillies, ${ }^{1}$ Juri Gelovani ${ }^{2}$ \\ ${ }^{1}$ H Lee Moffitt Cancer Center and Research Institute, Cancer Ecology, Tampa, FL, USA \\ ${ }^{2}$ University of Texas, MD Anderson Cancer Center, Houston, TX, USA
}

A $\mathrm{t}$ this years' World Molecular Imaging Congress (WMIC), we announced the merger of the Academy of Molecular Imaging (AMI) and the Society for Molecular Imaging (SMI) into the WMIS. This merger combines two complimentary societies dedicated to the development, advancement, and clinical translation of the nascent field of Molecular Imaging.

Both the AMI and SMI were established a decade ago, in 2001, in response to the need for an organizational framework for an emerging technology. An organizational framework was needed to provide forums for the sharing of ideas, development of curricula, and to identify potential applications for this burgeoning field. From the outset, the AMI and SMI approached the development of molecular imaging in parallel and in complimentary manners. The AMI provided a forum for the clinical utility of novel molecular imaging, primarily PET. The SMI provided a forum for the development of new molecular imaging agents and approaches for different imaging modalities and their applications to more basic, preclinical research. Over time, these two societies evolved to be more modality-neutral and focused on clinical translation.

In the fall of 2006, a meeting of representatives from both societies at the Chicago O'Hare Airport was held to discuss the potential merger of the two societies, termed the "le fusion" meeting. During this meeting, it was acknowledged that the two societies had complimentary missions and overlapping memberships. It was at this meeting that the concept of merging first the meeting, then the journal, and finally the administration made the most sense. Based on this trajectory, the first joint scientific conference of AMI and SMI was held in Providence, RI, in September of 2007. The following year, in September of 2008, the first WMIC was held in Nice, France, which was a great success, followed by the WMIC2009 in Montreal, Canada, the WMIC2010 in Kyoto, Japan, and the most recent WMIC2011 in San Diego, CA.

Two scientific peer-reviewed journals have emerged from these societies: the Journal of Molecular Imaging (MI) was published by SMI and Molecular Imaging and Biology was

Correspondence to: Robert Gillies; e-mail: robert.gillies@moffitt.org published by AMI. As part of the process of merger, both societies agreed to adopt Molecular Imaging and Biology as the joint official publication.

In March of 2010, Juri Gelovani, President of AMI, and Robert Gillies, President of SMI, met at an American Association for Cancer Research (AACR) conference held in Jordan to discuss and firm up the plans for the merger of AMI and SMI. The final agreement to proceed with the merger was achieved in Petra, Jordan, termed "The Petra Accord." The process of merging two administrative structures was not only daunting but was also a time for exciting change. A merger committee was formed chaired by Juri Gelovani and Robert Gillies, including three additional representatives from each society: John Kotyk, Michael Tweedle, and Kim Pierce represented the AMI; Jim Basilion, Zaver Bhujwalla, and Charles Metzger represented the SMI. In addition both Tim McCarthy (AMI) and Thomas Budinger (SMI) provided ad hoc counsel. This committee met face-to-face in Houston in July of 2010 to develop an overall structure of the new society and thereafter met weekly via T-Cons to draft a new set of bylaws and standard operating procedures (SOPs). As part of the opportunity, we were able to evaluate the bylaws and SOPs of existing societies to see what worked and what does not. Great thanks have to be made to Roberta Kravitz of the International Society for Magnetic Resonance in Medicine (ISMRM) and to Tom Budinger of the SMI who provided materials and insight into this process.

At the WMIC2011 in San Diego, we announced the merger of the administrative structures. The new entity, the WMIS, is now incorporated in the State of Nebraska and the Officers and Board Members were derived equally from those of the predecessor societies. Furthermore, we have retained copyrights on the logos and acronyms from both predecessor societies.

The WMIS Officers and Board of Trustees are:

President: Juri G. Gelovani, MD, PhD

Immediate Past President: Robert Gillies, PhD

President-Elect: Zaver Bhujwalla, PhD

Secretary: Michael Tweedle, PhD

Treasurer: James Basilion, PhD 
Board of Trustees:

Joseph Ackerman, PhD

Jeff Bulte, PhD

Edward Coleman, MD

Johannes Czernin, MD

John Kotyk, PhD

Gary Luker, MD, PhD

Chrit Moonen, PhD

Anna Moore, $\mathrm{PhD}$

Klaas Nicolay, PhD

Markus Rudin, PhD

Ren Shuan Liu, MD

June-Key Chung, MD

The WMIS covers the whole spectrum of molecular imaging-from target discovery, chemistry, molecular and cellular biology, in vivo imaging in animal models of various diseases using different imaging modalities, to pre-IND studies, phase I/II clinical studies under an IND, to phase IVtype studies, such as the National Oncology PET Registry (NOPR) clinical trials.

There will be some exciting changes in the WMIS that have been enabled by this merger:

- Foremost among these is to strengthen the WMIC meeting with a clearer mission and scope to promote and foster the blending of basic and translational sciences of molecular imaging that is inclusive of all modalities.

- Additional strengthening of our field will come from WMIS-sponsored or WMIS-endorsed meetings, such as Imaging in 2020, Interest Group workshops, WMIC satellite meetings, WMIS-sponsored symposia at other conferences (e.g., RSNA, AACR, RSNA, etc.), and international workshops/educational sessions in emerging areas. The WMIS will also work with sister societies to develop web-based curricular content.

- To reinforce our commitment to translational science, offices of clinical and regulatory affairs will assist in the development of new molecular imaging approaches from investigative to approved uses. This will build upon the success of NOPR to engage the FDA and CMS for approval of molecular imaging approaches including molecularly targeted probes from all major modalities.

- To encourage member participation, the formation of "interest groups" will allow subgroups to form around any common interest. These are intended to be research-focused international collaborative groups focused around a single theme, e.g., intraoperative MI, radiochemistry, imaging in 2020 , etc. A petition signed by 20 or more members is needed to form an Interest Group, and they are expected to have a span of 5 years, which is renewable. There are multiple benefits to forming an Interest Group:

- Space will be provided within the program (evenings) for Interest Group meetings.
- Organizational and fundraising support will be provided by the society office for Interest Group workshops.

- According to bylaws (Sect. 8.01), Nominating Committee membership shall be generated by the Interest Groups.

- At the WMIC, oral presentations and posters will be captured electronically and be available in perpetuity for all registrants, whether they attend the meeting or not.

The new WMIS is also committed to its education mission. We have set our strategic goals to advance education in molecular imaging across the whole spectrum of different disciplines, starting from chemistry and structural biology all the way to clinical practice. WMIS will expand the topics of educational courses and workshops at the WMIC annual meeting. Also, WMIS plans to co-organize educational and scientific sessions at the annual meetings, such as the Radiological Society of North America (RSNA), ISMRM, American Association for Cancer Research (AACR), American Society for Clinical Oncology, American Heart Association, World Pharma Congress, and others.

WMIS will spearhead the development of harmonized curricula in molecular imaging for residents, graduate, and postgraduate programs building on prior work by the European Society for Molecular Imaging (ESMI). A major multi-volume textbook in molecular imaging is planned in collaboration with Springer, which currently publishes the society's journal-Molecular Imaging and Biology.

The new Society is also meant to be international. Although this will take time to evolve, WMIS has strategic partnerships with both the ESMI and the Federations of Asian Societies for Molecular Imaging (FASMI). Both ESMI and FASMI will host the WMIC on a rotating basis.

We have set our strategic goals to expand WMIS activities in Asia. In particular, by working together with our colleges in Thailand, the WMIS has facilitated the establishment of the Society for Molecular Imaging of Thailand (SMITh). Also, the WMIS is currently involved in the organization of the 1st Annual Meeting of SMITh, which will be held in Bangkok in April 9-11, 2012. Dr. Bernd Pichler, Chairman of WMIC2012 Program Committee, together with Dr. Samlee Manhetkorn, President of SMITh, is developing an Educational and Scientific Program of the inaugural SMITh meeting.

Earlier this year, the Chinese Society for Molecular Imaging (CSMI) has been established. Drs. Gelovani and Gillies held an official meeting with Dr. Jie Tian, the first President of CSMI, at the WMIC2011 in San Diego at which the leaders have discussed the strategic opportunities for collaboration and expansion of molecular imaging in China. Recently, during a visit to China, Dr. Gillies met with Dr. Tian to continue discussion regarding the future of collaborative relationships between WMIS and CSMI.

The WMIC also plans to assist the organization of Molecular Imaging activities in India by bringing together several research groups involved in molecular imaging 
research and clinical practice around the former Indian Chapter of AMI. Over the next year, select representatives from the WMIS will continue working with colleagues in India to establish the Indian Society for Molecular Imaging.

During the recent meeting with the leadership of Korean Society for Molecular Imaging, Ms. Kim Pierce, Executive Director of WMIS, and Dr. Gelovani have visited the COEX Convention and Exhibition Center in Seoul, Korea, and firmed up the plans for the WMIC2014 venue. "Holding the WMIC2014 in Seoul will significantly improve the awareness about the importance of molecular imaging as the field of study and its role in clinical practice in Korea and whole South-East Asian region," said Prof. June-Key Chung, President of FASMI.

During the same trip to Asia, Ms. Pierce and Dr. Gelovani met with the leadership of Taiwanese Society of Molecular Imaging (TSMI) and inspected several potential venues for holding the WMIC in the future. "WMIC will have a significant educational impact on the new generation of researchers and clinical practitioners of molecular imaging in Taiwan," said Prof. Ren Shuan Liu, President of TSMI.

Last, but not least, the new WMIS is focused on clinical translation. We are dedicated to the proposition that the final arbiter of success will be the translation of MI probes into the clinic for the diagnosis and management of different diseases. WMIS will continue clinical studies initiated by
AMI including the NOPR for ${ }^{18} \mathrm{~F}-\mathrm{FDG}$ and ${ }^{18} \mathrm{~F}-\mathrm{NaF}$, as well as the clinical trial for ${ }^{18} \mathrm{~F}-\mathrm{NaF}$ required by $\mathrm{CMS}$ for approval of the reimbursement of PET imaging with ${ }^{18} \mathrm{~F}$ $\mathrm{NaF}$ for detection of bone metastases.

Along with several other stakeholders in academia and industry, such as Society of Nuclear Medicine and Medical Imaging Technology Association, WMIS is committed to active participation in The Coalition for PET Drug Approval.

The WMIC has been a dynamic and exciting meeting. We expect that the formation of the WMIS will only strengthen and improve the message, content, and excitement. This will require the continued partnership with our friends and colleagues in the ESMI and the FASMI. We have enjoyed fruitful partnerships with these Societies in the past and will continue to do so by alternating the WMIC between Europe, Asia, and North America on a regular basis. The 2011 European Molecular Imaging Meeting in Leiden was very vibrant, exciting, and scientifically rich. We have high expectations for the WMIC2012 in Dublin, Ireland. Based on the unqualified success of Kyoto, we also anticipate a fabulous meeting in Seoul in 2014. We are also committed to encouraging membership participation. These are your meetings and their success depends on a vibrant scientific exchange and a balanced program that you, the members, help forge. See you in Dublin! 